\title{
Beyond classic dermoscopic patterns of dermatofibromas: a prospective research study
}

\author{
Awatef Kelati, Nima Aqil, Hanane Baybay, Salim Gallouj and Fatima Zahra Mernissi
}

\begin{abstract}
Background: The usual stereotypical dermoscopic pattern associated with dermatofibromas is a pigment network and central white patch. However, this pattern may be difficult to diagnose in some variant cases. We aimed to describe dermoscopic patterns of dermatofibroma according to its histopathological subtypes, with special emphasis on new and rare dermoscopic features.

Methods: This prospective study, which was conducted between September 2015 and May 2016 in the Department of Dermatology, University Hospital Hassan II, Fez, Morocco, included 100 cases of dermatofibroma confirmed on clinical and histological grounds. Each lesion was scored for classic, previously reported, or new dermoscopic features.

Results: All our Moroccan patients had a dark skin phototype (Fitzpatrick scale types IV and V). A total of 14 morphological dermoscopic structures were distinguished, and 17 dermoscopic patterns were observed, with the most common pattern being the central white patch and peripheral pigment network (21\%). New patterns observed in our study were a white ring around an ulceration (6\%), a pigment network with a pigmented ring around follicular openings (2\%), and a discreet peripheral network and starlike white patch (3\%). A patchy network with white patches was significantly noted in atrophic dermatofibroma ( $p=0.01$ ); vascularization was described in both aneurysmal and hemosiderotic dermatofibromas ( $p=0.002)$; and a white ring around an ulceration was noted in aneurysmal dermatofibroma $(p<0.001)$.

Conclusions: We provide a description of dermoscopic patterns of dermatofibroma according to its histological subtypes in a dark skin phototype, along with a new report of a white ring around an ulceration as a significant pattern in aneurysmal dermatofibroma.
\end{abstract}

Keywords: Dermatofibroma, Variants, Dermoscopy, New dermoscopic patterns, Rare dermoscopic patterns

\section{Background}

Dermatofibroma (DF) or benign fibrous histiocytoma represents one of the most common skin tumors [1]; it accounts for approximately $3 \%$ of the skin biopsy specimens received at dermatology laboratories [2]. It is a neoplasm of the soft tissue and bone composed of fibroblastic and histiocytic components without any nuclear pleomorphism or histological anaplasia [3]. In addition to common fibrous histiocytoma, other variants have been described to date, including aneurysmal, hemosiderotic, cellular, epithelioid, atypical, lipidized, clear cell,

\footnotetext{
* Correspondence: awatkelati@gmail.com

Department of Dermatology, University Hospital Hassan II, Fez, Morocco
}

palisading, atrophic, keloidal, granular cell, myxoid, lichenoid, balloon cell, and signet ring cell variants, with the possibility of coexistence of histological features of several variants in the same lesion $[4,5]$. In its classical form as a small, raised, cutaneous nodule with a redbrown surface located on the limbs, DF is easy to diagnose clinically, but the diagnosis becomes difficult in variants and atypical cases. For this reason, it is important to improve other noninvasive diagnostic tools, especially dermoscopy.

A pigment network and a central white patch have been described as the typical appearance of common fibrous dermatofibromas (CFDFs) visualized by dermoscopy. When present, the pigment network and central white 
patch allow the examiner to confirm the diagnosis and set a conservative therapeutic approach [6], but in variants and atypical DFs, these features are not usually present. Our objective was to investigate the dermoscopic patterns of DF in our Moroccan population and to describe significant patterns related to different histopathological variants of DF.

\section{Methods}

We conducted a descriptive and analytical study of digital dermoscopic images of DF prospectively collected in the Department of Dermatology of the University Hospital Hassan II of Fez in Morocco during a period of 10 months from September 2015 to May 2016.

\section{Subjects}

Ninety-five Moroccan patients with 100 DFs were enrolled in the study. DF was confirmed either by clinical findings in CFDF with the classic dermoscopic pattern of pigment network and central white patch or on histological grounds in difficult and atypical cases of DF. The excision was also performed if the patient requested a histological confirmation.

\section{Data analysis}

Clinical data were obtained for each patient, including age and sex as well as the phototype, location, and size of the lesions. Dermoscopic images were documented with a digital camera (DermLite, 3Gen Inc., San Juan Capistrano, CA, USA; or Fotofinder, Bad Birnbach, Germany) with or without polarized light and with or without immersion. To avoid collapse of the vessels in the lesions, no pressure was used.

Clinical and dermoscopic data were analyzed and evaluated by two independent dermoscopists experienced in dermoscopy in our department. Clinical and dermoscopic images of atypical variants of DF confirmed on the basis of histology were retrospectively analyzed after excision. Dermoscopic features were divided into three categories: (1) classic with pigment network and central white patch, (2) previously reported patterns, and (3) new dermoscopic patterns.

Data extraction was performed using Excel software (Microsoft, Redmond, WA, USA). These data were then analyzed using IBM SPSS Statistics version 20 software (IBM, Armonk, NY, USA), and descriptive statistics were expressed as means and percentages. In the univariate analysis, the chi-square test was used to compare these percentages. A $p$ value less than 0.05 was considered statistically significant. All subjects were informed of the conditions related to the study and gave their informed consent.

\section{Results}

One hundred lesions in 95 Moroccan patients were evaluated. The average age of the patients was $40.3 \pm 8.7$ years old (range 17-56 years old), and there was a female predominance in our sample (63\%). All patients had dark skin based on Fitzpatrick skin phototypes (94\% phototype IV, $6 \%$ phototype V).

The lesions were located on the limbs in $75 \%$ of cases and on the back in $20 \%$ of cases. The lesions ranged in size from $0.5 \mathrm{~cm}$ to $10 \mathrm{~cm}$ in a case of a giant DF. The color varied from pink to light and dark brown. Twentynine percent of the lesions were nodular, and $50 \%$ were popular. Sixteen percent of the lesions were atrophic plaques, and $5 \%$ were tumors. Four histological subtypes

\section{Table 1 Dermoscopic structures of 100 dermatofibromas}

\begin{tabular}{|c|c|}
\hline Dermoscopic structures & No. (\%) \\
\hline Network & $79(79 \%)$ \\
\hline Peripheral & $45.8 \%$ \\
\hline Patchy & $17.7 \%$ \\
\hline Total & $15.5 \%$ \\
\hline White patches & $70(70 \%)$ \\
\hline Central scarlike & $40 \%$ \\
\hline Eccentric multiples & $30 \%$ \\
\hline Homogeneous pigmentation & $36(36 \%)$ \\
\hline Central & $26.9 \%$ \\
\hline Eccentric & $3.3 \%$ \\
\hline Peripheral & $5.8 \%$ \\
\hline Homogenous pink color & $21.1 \%$ \\
\hline Globule-like structures & $18(18 \%)$ \\
\hline White streaks & $18(18 \%)$ \\
\hline Peripheral rings & $13(13 \%)$ \\
\hline Around an ulceration & $5.5 \%$ \\
\hline Around the follicular openings & $2.2 \%$ \\
\hline Simple ring & $5.3 \%$ \\
\hline Brown & $10 \%$ \\
\hline White & $3 \%$ \\
\hline Ulceration & $6(6 \%)$ \\
\hline Brown streaks & $6(6 \%)$ \\
\hline Ringlike structures & $3(3 \%)$ \\
\hline Comedo-like opening & $3(3 \%)$ \\
\hline Negative network-like appearance & $3(3 \%)$ \\
\hline Heterogeneous pigmentation & $3(3 \%)$ \\
\hline Milia-like cysts & $2(2 \%)$ \\
\hline Vascular structures & $30(30 \%)$ \\
\hline Comma-like vessels & $23.3 \%$ \\
\hline Dotted vessels & $23.3 \%$ \\
\hline Linear & $13.3 \%$ \\
\hline
\end{tabular}


were distinguished: CFDF (72\% of cases), atrophic DF (17\%), aneurysmal DF (7\%), and hemosiderotic DF (4\%). Fourteen dermoscopic structures were described in our study: pigment network (79\% of cases), white patches (70\%), homogeneous pigmentation (36\%), white streaks $(18 \%)$, globule-like structures (18\%), peripheral ring (13\%), ulceration (6\%), brown streaks $(6 \%)$, ringlike structures and heterogeneous pigmentation (3\%),
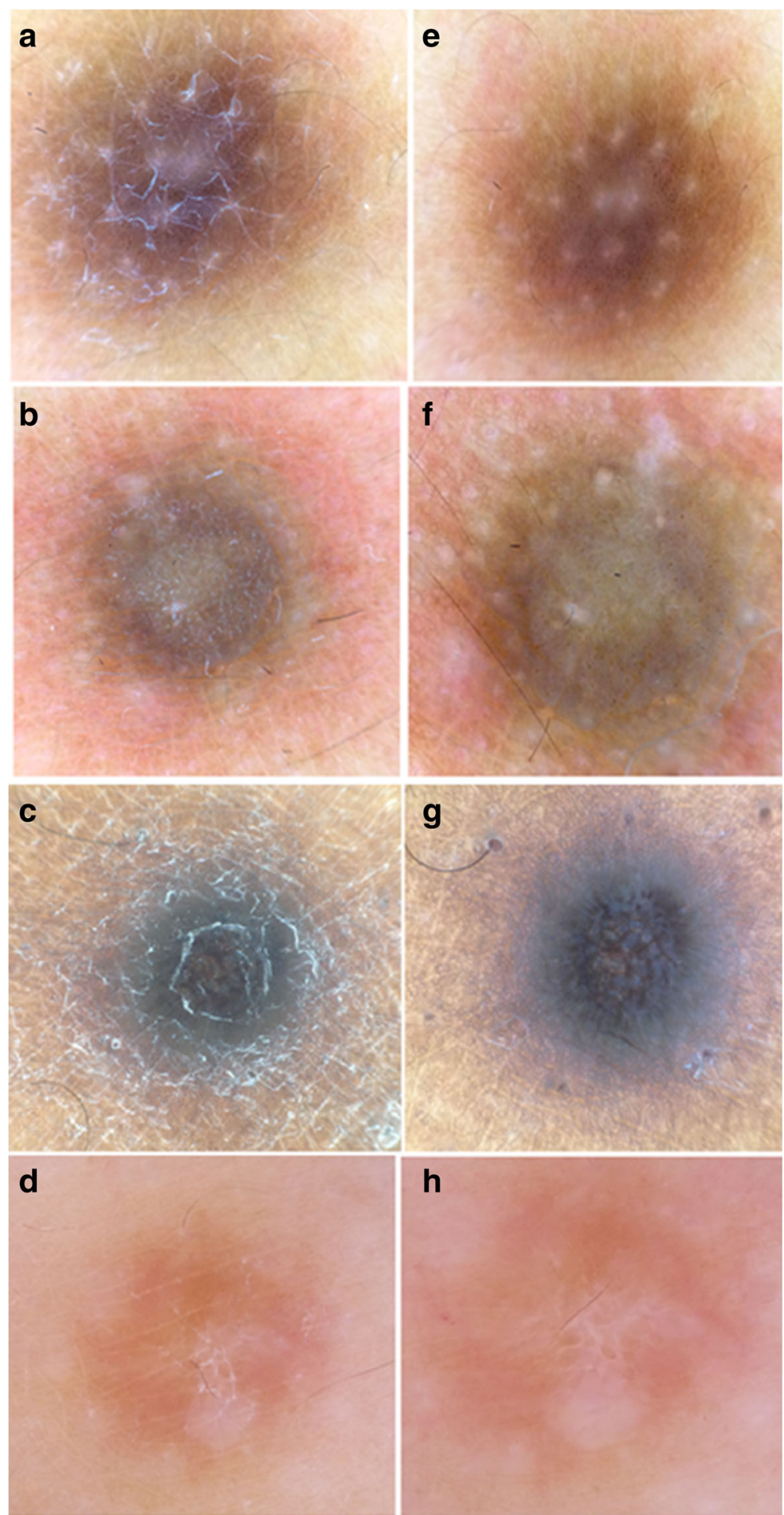

h

Fig. 1 a, b, c, d Before immersion. e, f, $\mathbf{g}, \mathbf{h}$ After immersion: better visualization of pigmented structures as peripheral network globules (e, f), pigmented streaks $(\mathbf{g})$, and an inverted network $(\mathbf{h})$ 
Table 2 Dermoscopic patterns of 100 dermatofibromas

\begin{tabular}{ll}
\hline Dermoscopic patterns & No. (\%) \\
\hline Classic & $21(21 \%)$ \\
Pigment network and central scarlike white patch & \\
Previously reported & $20(20 \%)$ \\
Multicomponent pattern & $16(16 \%)$ \\
Patchy network and multiple white patches & $12(12 \%)$ \\
Lentigo-like pattern & $9(9 \%)$ \\
$\begin{array}{l}\text { Central homogeneous pigmentation and peripheral } \\
\text { pigment network with or without white patches }\end{array}$ & $7(7 \%)$ \\
$\begin{array}{l}\text { Pink bluish homogeneous color with vascularization } \\
\text { with or without white patches }\end{array}$ & $3(3 \%)$ \\
$\begin{array}{l}\text { Total homogeneous pigmentation with or without white } \\
\text { structures }\end{array}$ & $2(2 \%)$ \\
$\begin{array}{l}\text { Peripheral homogeneous pigmentation and central white } \\
\text { scarlike patch }\end{array}$ & $3(3 \%)$ \\
Ringlike structures and central scarlike white patch & $1(1 \%)$ \\
Total white scarlike patch & $1(1 \%)$ \\
Peripheral homogeneous pigmentation or pigment \\
network and central negative network-like \\
$\begin{array}{l}\text { Seborrheic keratosis-like pattern } \\
\text { Heterogeneous pigmentation and multiple white patches }\end{array}$ \\
$\begin{array}{l}\text { New dermoscopic patterns } \\
\text { White ring around an ulceration } \\
\text { Pigment network with a ring around follicular openings } \\
\text { Discreet peripheral network and starlike white patch }\end{array}$ \\
\hline
\end{tabular}

comedo-like openings (3\%), inverted network (3\%), milialike cysts (2\%), and vascular structures (30\%) (Table 1).

Structures such as an inverted network, a discreet pigment network, globule-like structures, and brown streaks were visualized using immersion (Fig. 1).

Seventeen dermoscopic patterns were then distinguished, and they were divided into three categories: classic pattern with pigment network and central white patch (21\% of cases), previously reported patterns with multicomponent pattern (20\%), patchy network and multiple white patches (16\%), lentigo-like pattern (12\%), pink bluish pigmentation with vascularization (7\%), central homogeneous pigmentation and peripheral pigment network (9\%), total homogeneous pigmentation (3\%), ringlike structures and a central scarlike white patch (3\%), peripheral homogeneous pigmentation and central white scarlike patch (2\%), seborrheic keratosis-like pattern $(2 \%)$, total white scarlike patch $(1 \%)$, peripheral homogeneous pigmentation and central inverted network (1\%), and heterogeneous pigmentation and multiple white patches (1\%). New dermoscopic patterns were a white ring around an ulceration (6\% of cases), pigment network with a ring around the follicular openings (2\%), and a discreet peripheral network and starlike white patch (3\%) (Table 2 and Figs. 2, 3, 4, 5 and 6).

The aneurysmal variant of DF was significantly noted in men $(p=0.03)$, and it was also related to large lesions

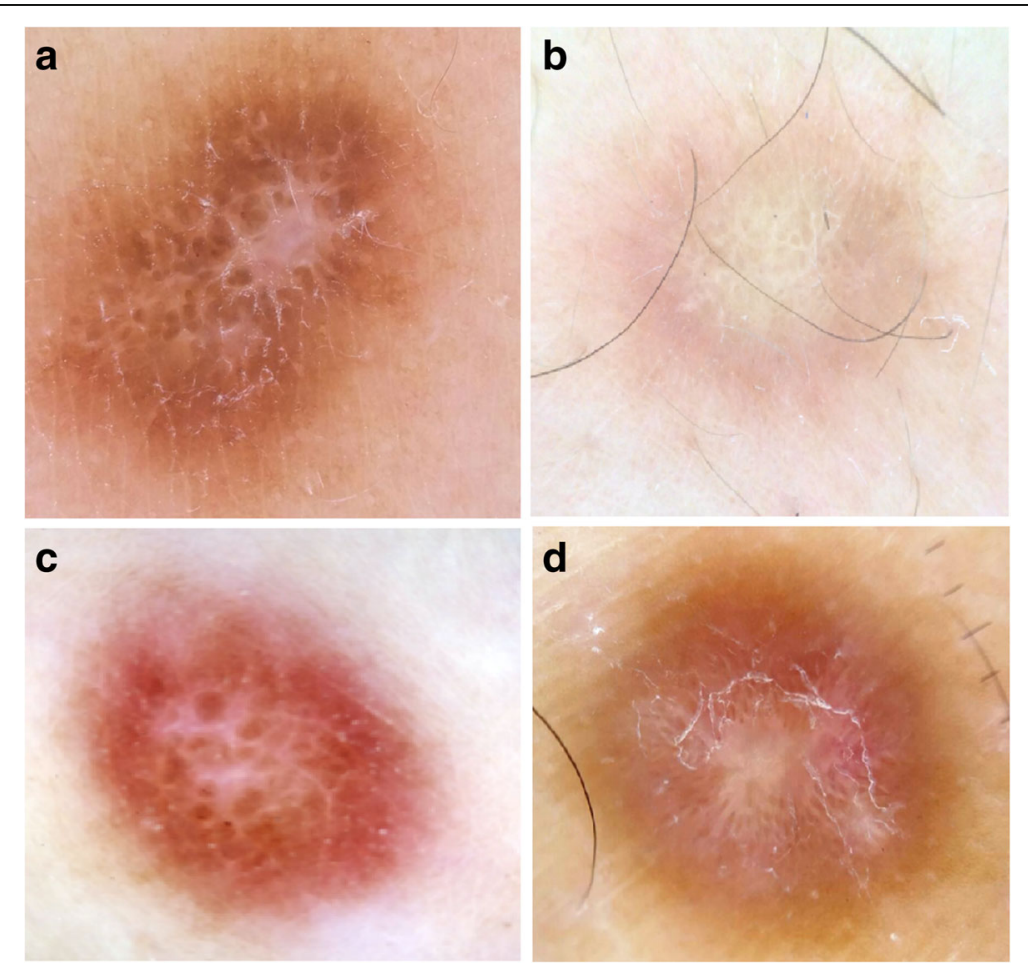

Fig. 2 a-d Classic dermoscopic patterns of common fibrous dermatofibroma: pigment network and central scarlike white patch with central globule-like structures 


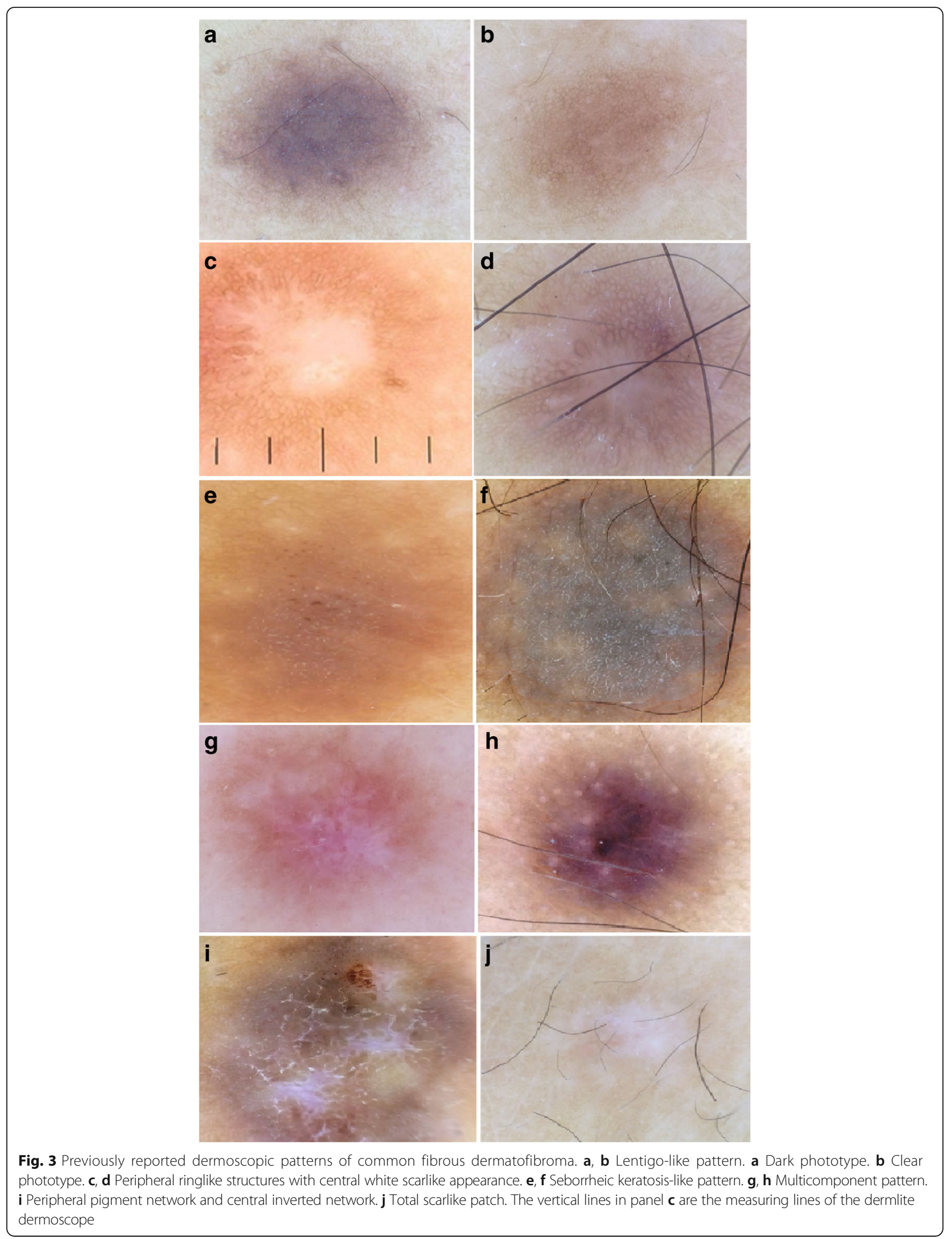




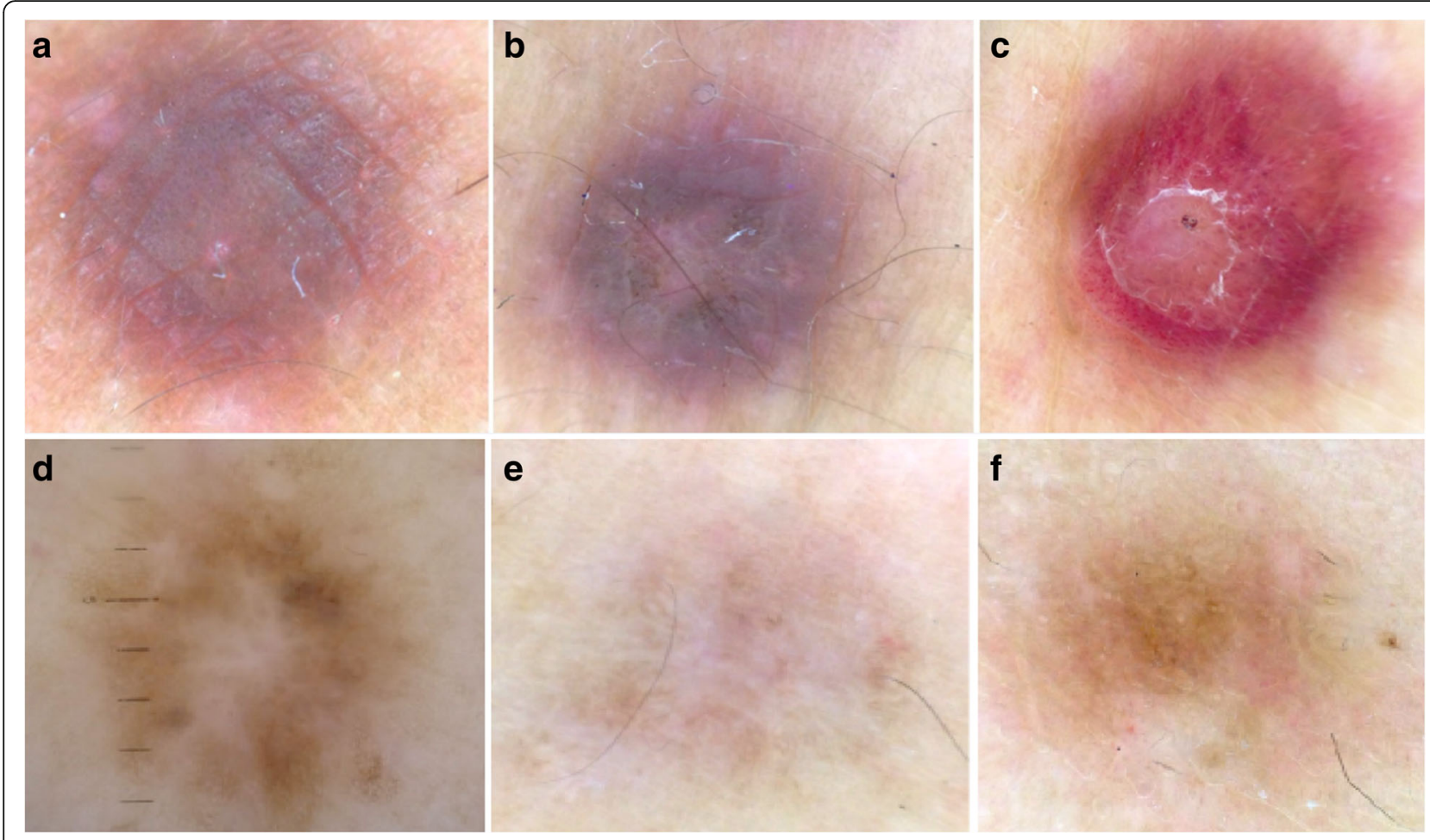

Fig. 4 a, b, c Dermoscopic patterns of hemosiderotic dermatofibroma: pink bluish pigmentation with the presence of dotted vessels and comma-like vessels. $\mathbf{d}$, e, $\mathbf{f}$ Dermoscopic patterns of atrophic dermatofibroma: patchy network and multiple white patches

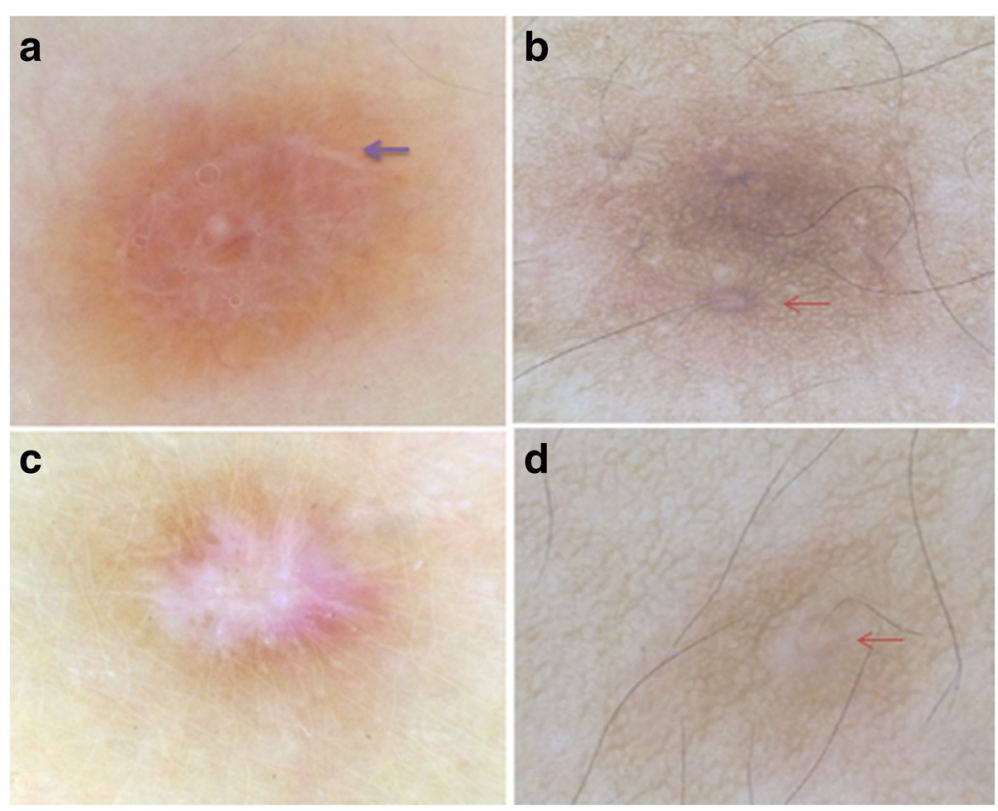

Fig. 5 News dermoscopic patterns of CFDF. a Total homogeneous pigmentation with white structures forming a ring (black arrow), b, d Pigmented network with a ring around the follicular openings (red arrow). c Discreet peripheral network and star like white patch 

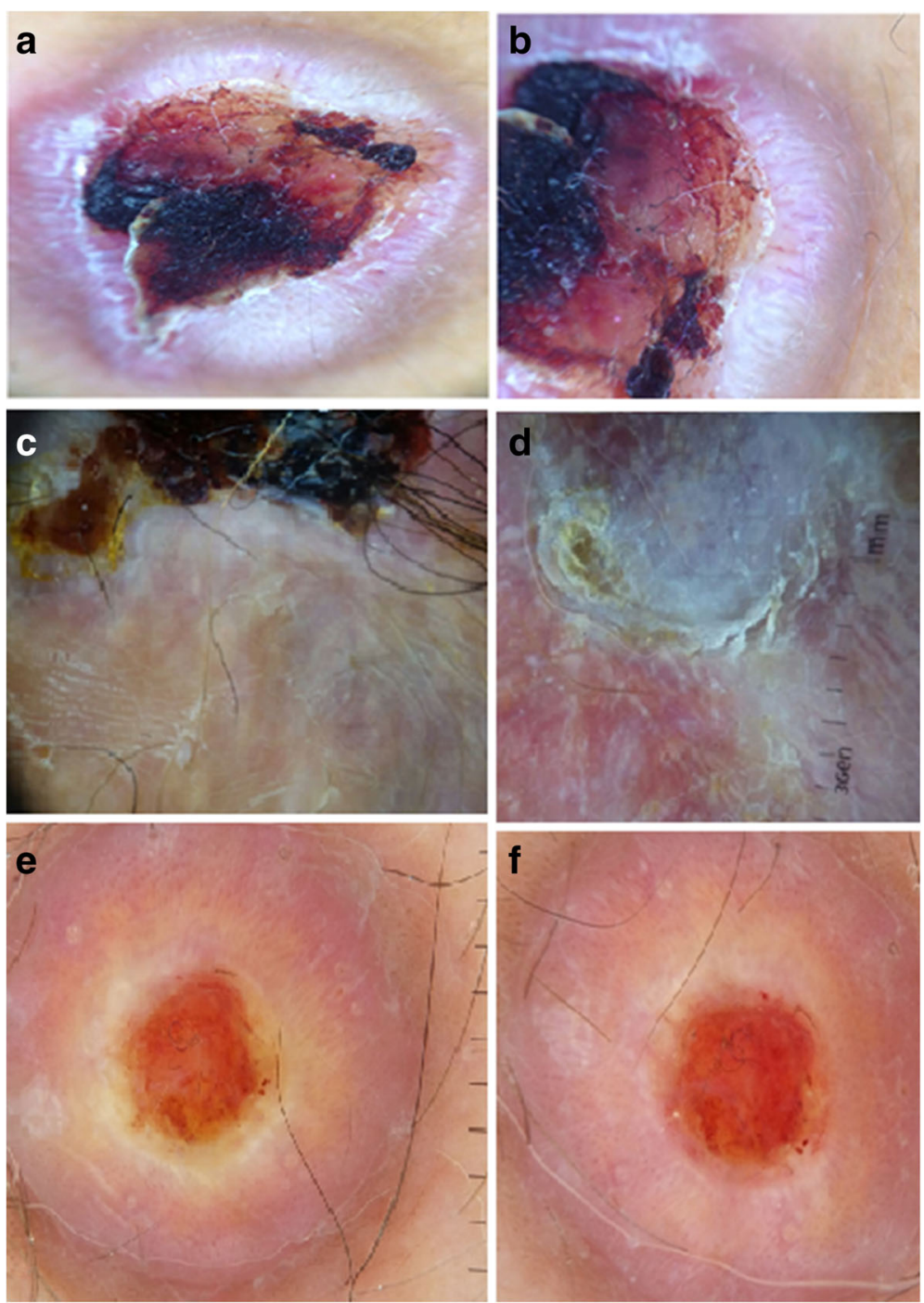

Fig. 6 New dermoscopic patterns of aneurysmal dermatofibroma: a-f: white ring around an ulceration with the presence of linear irregular vessels and dotted vessels. The horizontal lines in (e) are the measuring lines of the dermlite dermoscope

Table 3 Univariate analysis showing clinical and dermoscopic characteristics significantly related to different variants of dermatofibroma

\begin{tabular}{lllll}
\hline Variants of DF & Clinical characteristics & $p$ Value & Dermoscopic patterns & $p$ Value \\
\hline CFDF & None & & Peripheral pigment network and central white patch & $<0.001$ \\
& & & Homogeneous pigmentation and peripheral pigment network & 0.005 \\
& & & Lentigo-like pattern & 0.03 \\
& & & Total homogeneous pigmentation & 0.02 \\
Atrophic DF & Localization on the lower limbs & 0.002 & Patchy pigment network and multiple white patches pattern & 0.01 \\
Aneurysmal DF & Male sex & 0.03 & Vascular structures (linear irregular vessels) & 0.04 \\
& Big size of lesions & 0.04 & White ring around an ulceration & $<0.001$ \\
Hemosiderotic DF & Pink coloration & 0.004 & Vascular structures (dots and comma-like vessels) & 0.002 \\
\hline
\end{tabular}


Table 4 Review of the literature concerning dermoscopic patterns of dermatofibromas

\begin{tabular}{|c|c|c|c|c|c|}
\hline & $\begin{array}{l}\text { Zaballos et al. [15]: } \\
292 \text { patients } \\
412 \text { lesions }\end{array}$ & $\begin{array}{l}\text { Ferrari et al. [10]: } \\
115 \text { patients }\end{array}$ & $\begin{array}{l}\text { Agero et al. [14]: } \\
50 \text { patients }\end{array}$ & $\begin{array}{l}\text { Kilinc et al. [9]: } \\
52 \text { patients }\end{array}$ & $\begin{array}{l}\text { Present study: } \\
95 \text { patients } \\
100 \text { lesions }\end{array}$ \\
\hline \multicolumn{6}{|l|}{ Typical } \\
\hline $\begin{array}{l}\text { Peripheral delicate pigment network and central white } \\
\text { scarlike patch }\end{array}$ & $143(34.7 \%)$ & $23(17.7 \%)$ & $31(62 \%)$ & & $21(21 \%)$ \\
\hline Total delicate pigment network & $60(14.6 \%)$ & $4(3.1 \%)$ & & & \\
\hline $\begin{array}{l}\text { Peripheral delicate pigment network and central white } \\
\text { network }\end{array}$ & $37(9.0 \%)$ & $6(4.6 \%)$ & & & \\
\hline $\begin{array}{l}\text { Peripheral delicate pigment network and central } \\
\text { homogeneous pigmentation }\end{array}$ & $20(4.8 \%)$ & $5(3.8 \%)$ & & & $9(9 \%)$ \\
\hline Total white network & $9(2.2 \%)$ & $3(2.3 \%)$ & & & \\
\hline Total homogeneous pigmentation & $20(4.8 \%)$ & $15(11.5 \%)$ & & & $3(3 \%)$ \\
\hline Total white scarlike patch & $23(5.6 \%)$ & 0 & & & $1(1 \%)$ \\
\hline Multiple white scarlike patches & $24(5.8 \%)$ & $5(3.8 \%)$ & & & $16(16 \%)$ \\
\hline $\begin{array}{l}\text { Peripheral homogeneous pigmentation and central } \\
\text { white scarlike patch }\end{array}$ & $30(7.3 \%)$ & $10(7.7 \%)$ & & & $2(2 \%)$ \\
\hline $\begin{array}{l}\text { Peripheral homogeneous pigmentation and central } \\
\text { white network }\end{array}$ & $21(5.1 \%)$ & $11(8.5 \%)$ & & & $1(1 \%)$ \\
\hline \multicolumn{6}{|l|}{ Atypical } \\
\hline Multicomponent melanoma-like & $25(6.1 \%)$ & $38(29.2 \%)$ & & & $20(20 \%)$ \\
\hline Vascular tumor-like & & $21(16.2 \%)$ & & & \\
\hline BCC-like & & $6(4.6 \%)$ & & & \\
\hline Collision tumor-like & & $5(3.8 \%)$ & & & \\
\hline Psoriasis-like & & $3(2.3 \%)$ & & & \\
\hline Globules in scarlike area & & $3(2.3 \%)$ & & $20(38.5 \%)$ & \\
\hline Linear, irregular crypts & & & & $14(26.9 \%)$ & \\
\hline Lentigo-like pigment network & & & & $12(23 \%)$ & $12(12 \%)$ \\
\hline Homogeneous blue-gray pigmentation & & & & $3(5.9 \%)$ & \\
\hline $\begin{array}{l}\text { Erythematous homogeneous area surrounding white } \\
\text { patch }\end{array}$ & & & & $2(3.8 \%)$ & \\
\hline $\begin{array}{l}\text { Multiple scarlike structures with pigment network in a } \\
\text { patchy distribution (atrophic) }\end{array}$ & & & & $1(1.9 \%)$ & \\
\hline Central white patch & & & $42(84 \%)$ & & \\
\hline Peripheral pigment network & & & $36(72 \%)$ & & \\
\hline Globule-like structures & & & $22(44 \%)$ & & \\
\hline Blood vessels & & & $22(44 \%)$ & & \\
\hline Central pink hue or vascular blush & & & $5(10 \%)$ & & \\
\hline Peripheral diffuse pink to red to reddish violet halo & & & $14(28 \%)$ & & $7(7 \%)$ \\
\hline Peripheral halo of brown pigmentation & & & $2(4 \%)$ & & \\
\hline
\end{tabular}

Zaballos et al. [17] (6 cases)

Blue violaceous or red bluish homogeneous area with a white linear structure in the center and a delicate light brown pigment network with a few dotted vessels at the periphery

Blue yellowish homogeneous pattern with scaly surface in the center of the lesion surrounded by a yellowish homogeneous area at the periphery
4 Hemosiderotic dermatofibroma

1 Hemosiderotic dermatofibroma 
Table 4 Review of the literature concerning dermoscopic patterns of dermatofibromas (Continued)

\begin{tabular}{ll}
$\begin{array}{l}\text { Red brownish homogeneous area with a delicate light } \\
\text { brown pigment network at the periphery with } \\
\text { branched streaks and linear irregular dilated vessels in } \\
\text { other central areas }\end{array}$ & $\begin{array}{c}1 \text { Aneurysmal } \\
\text { dermatofibroma }\end{array}$ \\
$\begin{array}{l}\text { White ring around an ulceration } \\
\text { Pink bluish pigmentation with vascularization }\end{array}$ & 6 (6\%) \\
& Aneurysmal \\
dermatofibroma \\
Pigment network with a ring around follicular & 7 (7\%) \\
openings & Hemosiderotic \\
Discreet peripheral network and starlike white patch & dermatofibroma \\
\hline
\end{tabular}

$B C C$ Basal cell carcinoma

$(p=0.04)$. Atrophic DF was significantly localized in the lower limbs $(p=0.002)$. The pink coloration was related to the hemosiderotic DF $(p=0.004)$.

The four patterns significantly related to the classic type of DF were central white patch and peripheral pigment network, homogeneous pigmentation with peripheral pigment network, lentigo-like pattern, and total homogeneous pigmentation $(p \leq 0.02)$, whereas the pattern of patchy pigment network and multiple white patches was significantly described in atrophic DF $(p=0.01)$. Vascularization was described in both the aneurysmal and hemosiderotic DFs $(p \leq 0.04)$, and the aneurysmal DF was characterized by the white ring around an ulceration $(p<0.001)$ (Table 3$)$.

\section{Discussion}

DFs may display different morphological faces with different histological variants. In our study, these variants were atrophic DF, aneurysmal DF, and hemosiderotic DF. Although this benign tumor may mimic melanocytic lesions, especially melanoma in its atypical forms [7], the establishment of its significant dermoscopic patterns has developed at a far slower pace than melanocytic lesions because there are fewer than ten analytical studies on DF reported in the literature [8-14], compared with the large number of studies on melanocytic lesions.

The misdiagnosis of DFs as melanocytic lesions is probably more important in our population, owing to the fact that the patterns significantly related to this benign tumor were characterized by pigmented features such as a pigment network, homogeneous pigmentation with peripheral pigment network, a lentigo-like pattern, or total homogeneous pigmentation. This may be explained by the dark skin phototype of our patients, which increased the need for better characterization of DF in the dark phototype.

The pattern of a pigmented peripheral network and a central white scarlike patch was the most stereotypical and common finding of CFDF. It corresponds to pronounced fibrosis within the papillary dermis with hyperpigmented rete ridges at the edge of DF [9]. This pattern represented $62 \%$ of cases in the study of Agero et al. [14] and 34\% in the study of Zaballos et al. [15], whereas it was noted in only $21 \%$ of cases in our study. This may be explained by the particularity of the skin of our population, as stated above. Wide variation of patterns has been described in the literature and in our work on CFDF, although some of these patterns are very rare, such as the total white scarlike patch and the seborrheic keratosis-like pattern [9, 15, 16]. These must be known as possible presentations of this tumor in order to increase diagnostic accuracy.

Pink bluish pigmentation with vascularization was noted in hemosiderotic DFs in our study and in a case report by Zaballos et al. [17], whereas Blum et al. [9, 18] reported a pattern of an asymmetric blue grayish area with globules, a pigment network, and streaks without pink bluish coloration. The blue color was reported to correspond to the dermal pigmented siderophages, and the pink color in our study may correspond to the numerous small vessels, extravasated erythrocytes, and hemosiderin deposits [17]. The presence of vascular structures was also noted in aneurysmal DFs, which was similarly reported in one other study [15]. The patchy network and multiple white patches were noted in the atrophic variant of DF. This variant was rarely noted in other studies [14, 15], whereas it represented $16 \%$ of cases in our study (Table 4).

Furthermore, we defined new dermoscopic patterns such as a pigmented ring around the follicular openings in dark-skinned patients. This pigmented ring is different from the small ringlike structures or globule with a darker peripheral rim forming a kind of network, which corresponds to flattened and broad rete ridges, as previously reported by Zaballos et al. [15] and Agero et al. [14].

The white ring around an ulceration was highly related to aneurysmal DF in this study. It may be a very useful sign to differentiate between aneurysmal DF and achromic melanoma, especially because this variant of DF is also characterized by polymorphous vessels and linear 
irregular vessels, which may be confusing and misdiagnosed as a malignant tumor. So, in addition to the reported nonspecific signs of a central bluish or reddish homogeneous area with white structures and a peripheral delicate pigment network with vascular structures of variable degrees [9, 19], this ring pattern could be of great help in diagnosing difficult cases of aneurysmal DF.

The white color may be explained by the spindle cells' disposition and dermal fibrosis around the large bloodfilled spaces without endothelial lining [20]. If they are large and superficial, these hemorrhagic spaces may cause epidermal removal and ulceration surrounded by fibrosis, which appears as a white ring around the ulceration.

\section{Conclusions}

This study provides a description of dermoscopic patterns of DF according to histological subtypes in a dark skin phototype, with a new report of patterns such as the white ring around an ulceration as a significant one in aneurysmal DF.

\section{Acknowledgements}

We are indebted to all patients who participated in this study and gave their consent. We thank all the medical and paramedical staff of the Department of Dermatology and Anatomopathology for their enormous help.

\section{Availability of data and materials}

Please contact the corresponding author for data requests.

\section{Authors' contributions}

AK conceived of and designed the study. AK, NA, and HB acquired, analyzed, and interpreted data. AK, $\mathrm{HB}$, and NA drafted the manuscript. AK, SG, and FZM revised the manuscript critically for important intellectual content. All authors read and approved the final manuscript.

\section{Ethics approval and consent to participate}

Ethical approval was obtained from the ethics committee of the University Hospital Center Hassan II in Fez, Morocco, and all the subjects were informed of the conditions related to the study.

\section{Consent for publication}

Written informed consent was obtained from the patients for publication of this report and any accompanying images. A copy of the written consent is available for review by the Editor-in-Chief of this journal.

\section{Competing interests}

The authors declare that they have no competing interests.

\section{Publisher's Note}

Springer Nature remains neutral with regard to jurisdictional claims in published maps and institutional affiliations.

Received: 10 December 2016 Accepted: 20 August 2017

Published online: 20 September 2017

\section{References}

1. Crisan D, Gheuca Solovastru L, Crisan M, Badea R. Cutaneous histiocytoma histological and imaging correlations. A case report. Med Ultrason. 2014; 16(3):268-70.

2. Han TY, Chang HS, Lee JHK, Lee WM, Son SJ. A clinical and histopathological study of 122 cases of dermatofibroma (benign fibrous histiocytoma). Ann Dermatol. 2011;23(2):185-92.
3. Deb P, Singh V, Dutta V, Bhatoe HS, Chandran VM. Primary intracranial benign fibrous histiocytoma: report of an unusual case. J Cancer Res Ther. 2014;10(1):200-2.

4. Parish LC, Yazdanian S, Lambert WC, Lambert PC. Dermatofibroma: a curious tumor. Skinmed. 2012; 10(5):268-70

5. Parish LC, Yazdanian S, Lambert WC, Lambert PC. Dermatofibroma: a curious tumor. Skinmed. 2012;10(5):268-70.

6. Morariu SH, Suciu M, Vartolomei MD, Badea MA, Cotoi OS. Aneurysmal dermatofibroma mimicking both clinical and dermoscopic malignant melanoma and Kaposi's sarcoma. Rom J Morphol Embryol. 2014;55(3 Suppl): $1221-4$.

7. AlJasser MI, Martinka M, Kalia S. Dermatofibroma mimicking melanoma dermoscopically. Clin Exp Dermatol. 2014;39(1):69-70.

8. Arpaia N, Cassano N, Vena GA. Dermoscopic patterns of dermatofibroma. Dermatol Surg. 2005;31(10):1336-9.

9. Kilinc Karaarslan I, Gencoglan G, Akalin T, Ozdemir F. Different dermoscopic faces of dermatofibromas. J Am Acad Dermatol. 2007;57(3):401-6.

10. Ferrari A, Argenziano G, Buccini P, Cota C, Sperduti I, De Simone P, et al. Typical and atypical dermoscopic presentations of dermatofibroma. J Eur Acad Dermatol Venereol. 2013;27(11):1375-80.

11. Poulalhon N, Dalle $S$, Thomas L. Dermoscopic diagnosis of dermatofibromas [in French]. Ann Dermatol Venereol. 2008;135(12):886-7.

12. Zaballos P, Puig S, Malvehy J. Dermoscopy of atypical dermatofibroma: central white network. Arch Dermatol. 2006;142(1):126.

13. Puig S, Romero D, Zaballos P, Malvehy J. Dermoscopy of dermatofibroma. Arch Dermatol. 2005;141(1):122.

14. Agero ALC, Taliercio S, Dusza SW, Salaro C, Chu P, Marghoob AA. Conventional and polarized dermoscopy features of dermatofibroma. Arch Dermatol. 2006;142(11):1431-7

15. Zaballos P, Puig S, Llambrich A, Malvehy J. Dermoscopy of dermatofibromas: a prospective morphological study of 412 cases. Arch Dermatol. 2008;144(1):75-8.

16. Piccolo V, Mascolo M, Russo T, Russo D, Baroni A. Dermatofibroma with seborrheic keratosis-like changes: a dermoscopic challenge. J Am Acad Dermatol. 2014;71(4):e123-4.

17. Zaballos P, Llambrich A, Ara M, Olazarán Z, Malvehy J, Puig S. Dermoscopic findings of haemosiderotic and aneurysmal dermatofibroma: report of six patients. Br J Dermatol. 2006;154(2):244-50.

18. Blum A, Jaworski S, Metzler G, Bauer J. Lessons on dermoscopy: dermoscopic pattern of hemosiderotic dermatofibroma. Dermatol Surg. 2004;30(10):1354-5.

19. Yoshida Y, Miyachi M, Kiryu H, Kubota Y, Nakayama J. Dermoscopic features of aneurysmal benign fibrous histiocytoma. J Dermatol. 2005;32(8):688-90.

20. Alves JVP, Matos DM, Barreiros HF, Bártolo EAFLF. Variants of dermatofibroma a histopathological study. An Bras Dermatol. 2014;89(3):472-7.

Submit your next manuscript to BioMed Central and we will help you at every step:

- We accept pre-submission inquiries

- Our selector tool helps you to find the most relevant journal

- We provide round the clock customer support

- Convenient online submission

- Thorough peer review

- Inclusion in PubMed and all major indexing services

- Maximum visibility for your research

Submit your manuscript at www.biomedcentral.com/submit
C Biomed Central 